\title{
Pilot Experience with ABO-Incompatible Kidney Transplantation as a Second Transplant
}

\author{
Junji Uchida ${ }^{a} \quad$ Akihiro Kosoku $^{a}$ Kazuya Kabei ${ }^{a}$ Shunji Nishide ${ }^{a}$ \\ Hisao Shimada ${ }^{a}$ Tomoaki Iwai ${ }^{a}$ Nobuyuki Kuwabara ${ }^{a}$ Toshihide Naganuma ${ }^{a}$ \\ Keiko Maeda ${ }^{b}$ Yuki Yoshikawac Norihiko Kumadad Yoshiaki Takemoto ${ }^{a}$ \\ Tatsuya Nakatani ${ }^{a}$ \\ a Department of Urology, Osaka City University Graduate School of Medicine, Osaka, Japan; ${ }^{b}$ Department of Nursing, \\ Osaka City University Hospital, Osaka, Japan; ' Osaka City University Medical School Skills Simulation Center, Osaka, \\ Japan; ${ }^{\text {DDepartment }}$ of Urology, Suita Municipal Hospital, Osaka, Japan
}

\section{Keywords}

Second transplantation · Kidney · ABO-incompatible

\begin{abstract}
Background: Despite advances in immunosuppressant medications, improvement in long-term survival for kidney transplant recipients has been more difficult to achieve. In fact, the number of patients with failing grafts who must either return to dialysis or undergo a second transplant is increasing. Second transplantation is associated with reduced mortality rates compared to remaining on dialysis after an initial graft loss. Nowadays, excellent ABO-incompatible kidney transplant outcomes have been achieved. However, there have been no reports on $\mathrm{ABO}$-incompatible kidney
\end{abstract}

\begin{tabular}{ll}
\hline KARGER & $\begin{array}{l}\text { (c) } 2019 \text { The Author(s) } \\
\text { Published by S. Karger AG, Basel }\end{array}$ \\
E-Mail karger@karger.com & This article is licensed under the Creative Commons Attribution- \\
www.karger.com/uin & $\begin{array}{l}\text { NonCommercial-NoDerivatives 4.0 International License (CC BY- } \\
\text { NC-ND) (http://www.karger.com/Services/OpenAccessLicense). } \\
\text { Usage and distribution for commercial purposes as well as any dis- } \\
\text { tribution of modified material requires written permission. }\end{array}$
\end{tabular}

transplantation as a second transplant. Patients and Methods: Three patients who received their graft from an ABOincompatible living donor at our institution as a second transplant were enrolled in this study. We focused on immunosuppressive therapy for second ABO-incompatible kidney transplantation, donor-specific antibody status before the second transplant, patient and graft survivals, and complications. Results: All 3 patients successfully underwent ABOincompatible kidney transplantation as a second transplant with a follow-up period of 141, 39, and 24 months. Patient and graft survival rates were $100 \%$. Conclusions: ABO-incompatible kidney transplantation may be an acceptable treatment for patients who need a second renal replacement therapy after their initial graft failure.

(c) 2019 The Author(s)

Published by S. Karger AG, Basel

Junji Uchida, MD, PhD

Department of Urology

Osaka City University Graduate School of Medicine

1-4-3, Asahi-machi, Abeno-ku, Osaka 545-8585 (Japan)

E-Mail m9492120@msic.med.osaka-cu.ac.jp 


\section{Introduction}

Great progress has been achieved in all aspects of kidney transplantation, resulting in a significant improvement in allograft survival. Nowadays, the 5 -year graft survival of living donor kidney transplant recipients has reached as high as $90 \%$ in Japan [1]. However, improvement in long-term survival has been difficult to achieve in spite of significant advances in medical treatment for kidney transplantation [2]. An increasing number of transplant failure patients will therefore become potential candidates for second renal replacement therapy. Second kidney transplants have increased the life expectancy of initial kidney transplant recipients, having better prognosis compared to returning to dialysis. However, it is even more difficult to have access to a second kidney transplant due to human leukocyte antigen (HLA) sensitization and organ shortage [3].

Due to the shortage in deceased donors, $\mathrm{ABO}$-incompatible kidney transplantation has been performed since the late 1980s in Japan. Excellent outcomes have been achieved, and recently, there have been no significant differences in transplant outcomes between ABO-incompatible and $\mathrm{ABO}$-compatible kidney transplantation [4, 5]. Although this procedure may become an acceptable option for second kidney transplantation, there have been no reports regarding $\mathrm{ABO}$-incompatible kidney transplantation as a second transplant.

Second kidney transplant recipients may have a lower graft survival than initial transplant recipients, considering that second kidney transplantation is high risk for graft failure, mainly related to elevated levels of preformed HLA antibodies [6]. Moreover, ABO-incompatible kidney transplantation is a high-risk procedure due to anti-A/B antibodies [4]. In this pilot study, we demonstrated our experience with $\mathrm{ABO}$-incompatible kidney transplantation as a second transplant, focusing on desensitization protocols, outcomes, and complications.

\section{Materials and Methods}

Three patients who received their graft from an $\mathrm{ABO}$-incompatible living donor at our institution as a second transplant between January 2007 and December 2016 were enrolled in this study. All patients were followed until November 2018. We collected the causes of end-stage kidney disease, duration of dialysis before initial transplantation, initial graft survival period, immunosuppressive therapy at initial transplantation, and causes of initial graft failure, and conducted flow cytometry cross-match
(FCXM) and flow screening panel reactive antibody (PRA) tests on all patients before the second transplant to detect anti-HLA antibodies or donor specific antibodies (DSA). FCXM and flow PRA were performed around 3 months before transplantation, as initial FCXM and flow PRA. If initial FCXM and flow PRA were both negative, preoperative FCXM and flow PRA were not performed. In cases of a positive FCXM, Luminex single antigen beads assay was performed to assess DSA strength using mean fluorescence intensity (MFI). In cases of positive PRA, we also verified if antiHLA antibodies detected by PRA were DSA or non-DSA using Luminex single antigen beads assay. A median ratio $<1.4$ for $\mathrm{T}$-cell FCXM was defined as negative. We also measured anti-A/B antibody titers using the saline agglutination technique for IgM and the indirect Coomb's test for IgG. Our criteria for implementation of a second kidney transplant were negative T-cell FCXM and/or MFI value less than 3,000 on Luminex single antigen beads assay and preoperative anti-A/B antibody titers less than $\times 64$. In this study, we focused on immunosuppressive therapy for second ABO-incompatible kidney transplantation, DSA status before the second transplant, patient and graft survivals, and complications.

Our study was approved by the Ethics Committee of Osaka City University Graduate School of Medicine (No. 3957). Opt-out consent was obtained instead of written informed consent. We provided patients with information explaining the proposed research plan (the purpose, required individual data, and duration of research) by means of an information website of our hospital and gave them the opportunity of opting out. All the procedures were in accordance with the Helsinki Declaration of 2000 and the Declaration of Istanbul 2008.

\section{Immunosuppressive Protocol}

Desensitization protocols for ABO-incompatible kidney transplantation have been developed over time, and we have utilized the optimal protocol available at the time [7-13]. As our present standard desensitization protocol to remove the anti-A/B antibodies, the patients underwent plasmapheresis prior to kidney transplantation until the antibody titers were less than 1:16. The patients received splenectomy (before 2006), 1 (after January 2012) or 2 doses (before December 2011) of rituximab (RIT; $150 \mathrm{mg} / \mathrm{m}^{2}$ ) prior to transplantation to inhibit antibody production. Our desensitization protocol was modified depending on age $[7,9]$, rebound of antibody titers, baseline antibody titer or preexisting DSA [12, 13]. The basic protocol for $\mathrm{ABO}$-incompatible kidney transplantation we currently use is shown in Figure 1. Before transplantation, antimetabolite, or mammalian target of rapamycin inhibitor was administered for 2 weeks to suppress B cell lymphocytes.

For treatment of acute cellular rejection episodes, methylprednisolone was administered at a dose of $500 \mathrm{mg} /$ day for 3 days alone or in combination with deoxyspergualin $(5 \mathrm{mg} / \mathrm{kg} / \mathrm{day}$ : 5-7 days). When resistance to these drugs was confirmed, antihuman thymocyte immunoglobulin or OKT-3 was administered. For treatment of antibody-mediated rejection, plasmapheresis was performed, and RIT was administered. Acute cellular rejection and antibody-mediated rejection were histologically diagnosed by light microscopy of graft biopsy specimens according to the Banff 2007-2013 criteria. Surveillance biopsies were performed once within 3 months after surgery or before discharge from hospital in all patients. When clinically indicated by rising serum creatinine or decreasing urine output, episode biopsies were performed. 


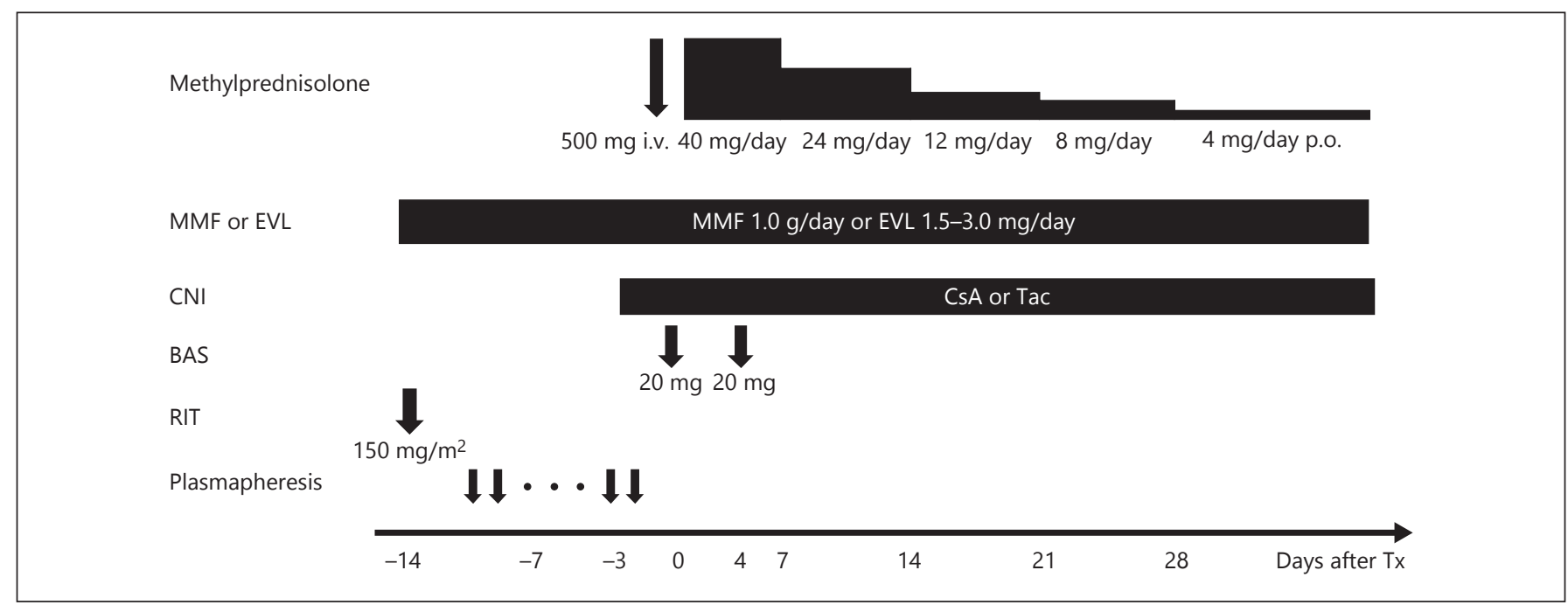

Fig. 1. Immunosuppressive protocol for standard ABO-incompatible kidney transplantation. i.v., intravenous; p.o., per oral; MMF, mycophenolate mofetil; EVL, everolimus; CNI, calcineurin inhibitor; Tac, tacrolimus; CsA, cyclosporine; BAS, basiliximab; RIT, rituximab; Tx, transplantation.

Table 1. Patient characteristics 1

\begin{tabular}{|c|c|c|c|c|c|c|c|}
\hline & $\begin{array}{l}\text { Age at initial } \\
\text { Tx, years }\end{array}$ & Gender & $\begin{array}{l}\text { Door age at } \\
\text { initial Tx, years }\end{array}$ & $\begin{array}{l}\text { Donor at } \\
\text { initial Tx }\end{array}$ & $\begin{array}{l}\text { Cause of end-stage } \\
\text { kidney disease }\end{array}$ & $\begin{array}{l}\text { Duration of } \\
\text { dialysis, month }\end{array}$ & $\begin{array}{l}\text { HLA } \mathrm{mm} \text { at } \\
\text { initial } \mathrm{Tx} \text {, antigen }\end{array}$ \\
\hline Case 1 & 20 & Female & 45 & Mother & Chronic glomerulonephritis & 4 & $3 / 6$ \\
\hline Case 2 & 19 & Male & 45 & Mother & Chronic glomerulonephritis & 20 & $3 / 6$ \\
\hline Case 3 & 27 & Female & 54 & Father & IgA nephropathy & 3 & $3 / 6$ \\
\hline
\end{tabular}

HLA, human leukocyte antigen; Tx, transplantation; mm, mismatch.

Table 2. Patient characteristics 2

\begin{tabular}{|c|c|c|c|c|c|c|c|}
\hline & $\begin{array}{l}\text { CNI at } \\
\text { initial } \\
\text { Tx }\end{array}$ & $\begin{array}{l}\text { Antimetabolite } \\
\text { at initial Tx }\end{array}$ & $\begin{array}{l}\text { ABO- } \\
\text { incompatibility } \\
\text { at initial } \mathrm{Tx}\end{array}$ & $\begin{array}{l}\text { B cell } \\
\text { depletion } \\
\text { at initial Tx }\end{array}$ & $\begin{array}{l}\text { Duration of } \\
\text { initial graft } \\
\text { survival, month }\end{array}$ & $\begin{array}{l}\text { Cause of initial } \\
\text { graft failure }\end{array}$ & $\begin{array}{l}\text { Dialysis duration } \\
\text { between initial graft failure } \\
\text { and second Tx, month }\end{array}$ \\
\hline Case 1 & Tac & MMF & Compatible & _- & 35 & Chronic rejection & 6 \\
\hline Case 2 & CsA & Azathioprine & Compatible & - & 275 & Chronic rejection & 17 \\
\hline Case 3 & $\mathrm{Tac}$ & MMF & Incompatible $(\mathrm{AB} \rightarrow \mathrm{A})$ & $\overline{\text { Splenectomy }}$ & 185 & $\begin{array}{l}\text { Recurrent IgA nephropathy, } \\
\text { CMV colitis }\end{array}$ & 10 \\
\hline
\end{tabular}

CNI, calcineurin inhibitor; Tx, transplantation; Tac, tacrolimus; CsA, cyclosporine; MMF, mycophenolate mofetil; CMV, cytomegalovirus.

\section{Results}

\section{Patient Characteristics}

The patient characteristics before the second transplant are shown in Tables 1 and 2. The dialysis duration of case 1,2 , and 3 was 4,20 , and 5 months respectively.
The causes of end-stage kidney disease were chronic glomerulonephritis (case 1,2), and IgA nephropathy (case 3 ). One patient (case 3) also underwent ABO-incompatible kidney transplantation as the initial transplant and received splenectomy for B-cell depletion. The durations of initial graft survival were 35,275 , and 185 months, re- 
spectively, for cases 1,2 , and 3 . The causes of the initial graft failure were chronic rejection (cases 1 and 2) and recurrent glomerulonephritis (IgA nephropathy) and cytomegalovirus (CMV) colitis (case 3). Dialysis duration between the initial graft failure and the second transplant was 6,17 , and 10 months, respectively, for cases 1,2 , and 3. All recipients did not receive initial kidney allograftectomy.

\section{Immunosuppressive Therapy for Second}

Transplantation and Donor-Specific Antibody Status before Second Kidney Transplantation

Histocompatibility, ABO-incompatibility, and immunosuppressive therapy for second transplantation are shown in Table 3. DSA status including FCXM, PRA, and single antibodies, and anti- $\mathrm{A} / \mathrm{B}$ antibody titers are given in Table 4.

Case 1 received both splenectomy and administration of 2 doses of RIT due to high anti-A/B antibody titers $(\operatorname{IgG} \times 256, \operatorname{Ig} M \times 512)$. To remove the anti-A/B antibody titers, this patient received 11 sessions of plasmapheresis. Levels of class I and II PRA were not detectable and 68.3\%, respectively, at initial assessment before her second transplant. However, because there were 6 HLA antigen matches between this patient and the second donor and she showed negative T cell FCXM, this patient was confirmed to have no preexisting DSA without conducting Luminex single antigen beads assay. Therefore, preoperative FCXM and flow PRA were not performed in case 1.

In case 2, levels of class I and II PRA were not detectable and $20.3 \%$, respectively, although the result of $\mathrm{T}$ cell FCXM was negative, and Luminex single antigen beads assay revealed preexisting DSA (DQ4 MFI 7754, DR4 MFI 1639 ) at his second transplant before desensitization. Anti-A/B antibody titers were IgG $\times 64$ and IgM $\times 32$ respectively. He received both splenectomy and administration of single dose RIT and underwent 11 sessions of plasmapheresis to remove preexisting DSA and anti-A/B antibodies. Because the MFI value of DQ4 became $<3,000$ after desensitization, the second transplant was performed.

Case 3 who had already received splenectomy at the initial transplant underwent only administration of RIT for B-cell depletion at her second transplant. She was affected by intractable cytomegalovirus colitis during the terminal stage of initial kidney transplantation and treated with administration of valgancyclovir. After the initial graft failure, she had received steroid and low dose tacrolimus (Tac) to prevent development of anti-HLA antibodies. All tests for detection of DSA were negative, and she had relatively low ani-A/B antibody titers before her second transplant. She received everolimus (EVL) and reduced Tac exposure, and prophylaxis administration of valgancyclovir to prevent cytomegalovirus infection.

\section{Outcomes and Complications}

The outcomes and complications of the second transplant are shown in Table 5. All patients successfully underwent $\mathrm{ABO}$-incompatible kidney transplantation as second transplantation. Median follow-up period was 141, 39, and 24 months, respectively, for cases 1, 2, and 3. Patient and graft survival rates were $100 \%$ during follow-up period. The current estimated glomerular filtration rate was 24.75 , 54.18 , and $55.19 \mathrm{~mL} / \mathrm{min} / 1.73 \mathrm{~m}^{2}$, respectively, for cases 1 , 2 , and 3. One patient (case 2) had acute cellular rejection classified as Banff IA during the follow-up period. One recipient (case 1) experienced cytomegalovirus reactivation revealed by cytomegalovirus antigenemia. However, no obvious invasive tissue disease occurred. Although the patient in case 3 was affected by intractable CMV colitis before second transplantation, she has not experienced CMV infection since second transplantation. She has received administration of EVL with Tac minimization and administered prophylaxis valganciclovir administration for 6 months after second transplantation. The patient in case 3 experienced adenovirus cystitis. No recipients developed any other opportunistic infection such as BK virus and pneumocystis jirovecii during the follow-up period. The patient in case 1 experienced transplanted ureteral stenosis and was treated with ureteral balloon dilatation.

\section{Discussion/Conclusion}

The present pilot study revealed our outcomes of second $\mathrm{ABO}$-incompatible kidney transplantation. All of our patients underwent successful transplantation without severe complications or rejection, although this procedure can carry a high immunological risk due to ABOincompatibility and possible elevated levels of preformed HLA antibodies. To our knowledge, this may be the first demonstration of $\mathrm{ABO}$-incompatible kidney transplantation as a second transplant. Our results suggested that this procedure may be an acceptable treatment for patients who need a second renal replacement therapy after their first graft failure.

Because a large end-stage kidney disease population and severe organ shortage have resulted in waiting times for deceased donor kidney transplantation close to 15 years in Japan, ABO-incompatible kidney transplantation has become a reasonable alternative for end-stage 


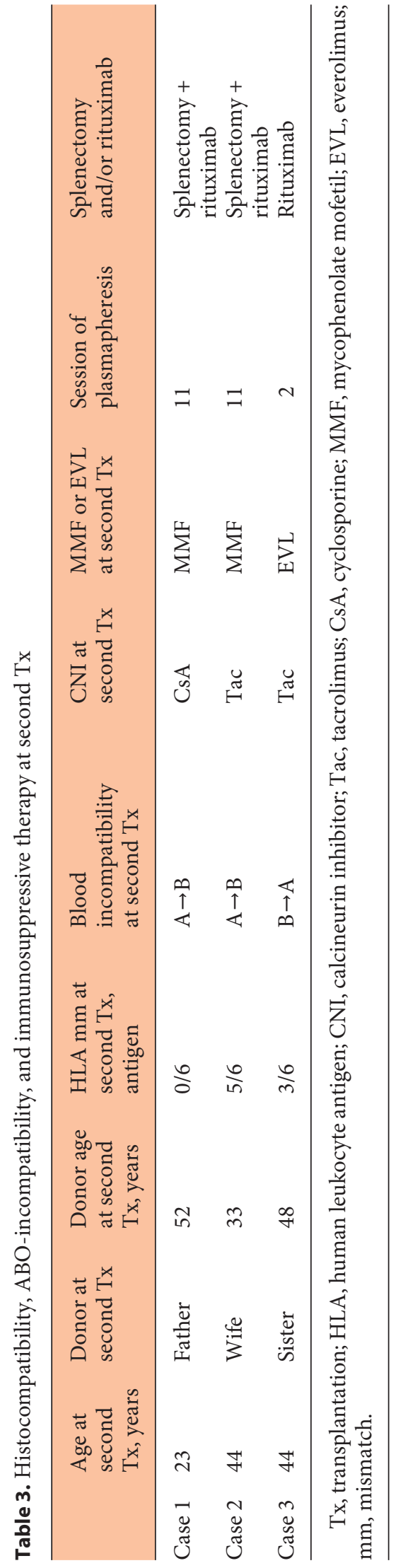

ABO-Incompatible Kidney

Retransplantation

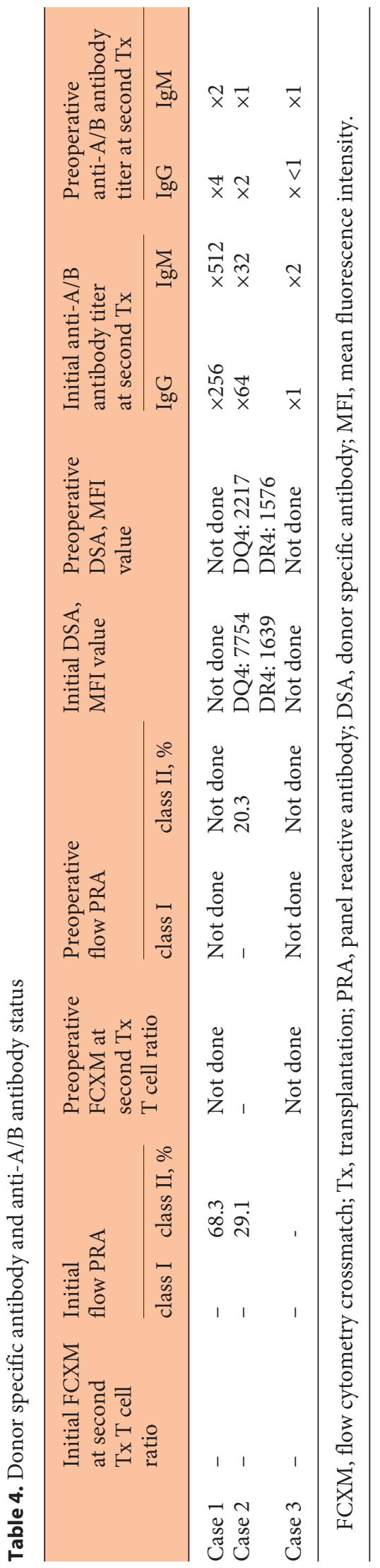

Urol Int 2019;102:441-448 
Table 5. Outcomes and complications

\begin{tabular}{lllllllll}
\hline & $\begin{array}{l}\text { Patient } \\
\text { survival }\end{array}$ & $\begin{array}{l}\text { Graft } \\
\text { survival }\end{array}$ & $\begin{array}{l}\text { Follow-up } \\
\text { duration, } \\
\text { month }\end{array}$ & $\begin{array}{l}\text { Current } \\
\text { SCr, mg/dL }\end{array}$ & $\begin{array}{l}\text { Current eGFR, } \\
\mathrm{mL} / \mathrm{min} / 1.73 \mathrm{~m}^{2}\end{array}$ & $\begin{array}{l}\text { Acute cellular } \\
\text { rejection }\end{array}$ & $\begin{array}{l}\text { Antibody } \\
\text { mediated } \\
\text { rejection }\end{array}$ & $\begin{array}{l}\text { CMV } \\
\text { antigenemia complications }\end{array}$ \\
\hline Case 1 & Yes & Yes & 141 & 1.98 & 24.75 & - & - & + \\
Case 2 & Yes & Yes & 39 & 1.17 & 54.18 & + & - & $-\begin{array}{l}\text { Ureteral stenosis } \\
\text { Adenovirus } \\
\text { cystitis }\end{array}$ \\
Case 3 & Yes & Yes & 24 & 1.22 & 55.19 & - & - & - \\
\hline
\end{tabular}

SCr, serum creatinine; eGFR, estimated glomerular filtration rate; CMV, cytomegalovirus.

kidney disease patients with an $\mathrm{ABO}$-incompatible living donor, the outcomes of which have nearly equaled those of ABO-compatible kidney transplantation [4, 5]. Moreover, our recent report showed that $\mathrm{ABO}$-incompatible kidney transplantation may be an effective treatment for patients even at a low-volume institution where only about 2 kidney transplants a month are performed on average [14]. ABO-incompatible kidney transplantation is an established renal replacement therapy for end-stage kidney disease $[5,14]$, and patients receiving living donor grafts have longer patient and graft survival rates than those receiving deceased donor grafts [15]. ABO-incompatible kidney transplantation may therefore be an alternative treatment as a second transplant.

Nowadays, second transplantation provides an optimal treatment for long-term survival and quality of life in patients facing allograft loss as compared to maintenance dialysis therapy $[3,16]$. Moreover, recent improvements in immunosuppressive therapy may have contributed to attaining no significant differences in outcomes between first transplantation and second transplantation [17]. However, second transplant recipients have a higher PRA level compared to initial transplant recipients [6]. In highly sensitized patients, the immunologic barrier is associated with an increased risk of antibody-mediated rejection and poor graft survival. Recently, living donor kidney transplantation after desensitization has been reported to provide a significant survival benefit for patients with HLA sensitization, as compared with waiting for a compatible organ $[18,19]$. The regimen for $\mathrm{ABO}$ incompatible kidney transplantation including plasmapheresis for removal of anti-A/B antibodies and administration of RIT for inhibition of antibody production may be useful for desensitization in second transplantation, which may have a higher risk related to increased levels of preformed HLA antibodies or non-HLA antibodies that might cause damages of the graft.
The relationship between increasing waiting time before first transplantation and inferior transplant outcomes has been well established [20]. A previous report showed that increasing waiting time after first graft failure and before second transplantation was associated with greater risk of early and severe acute rejection episodes, overall graft failure, all-cause mortality, and death with a functioning graft, independent of donor and recipient age, HLA mismatches, and initial immunosuppression [21]. Another report showed that preemptive transplantation was associated with a lower risk of second transplant failure from any cause including death [22]. Increasing waiting time between first graft failure and second transplantation may therefore be an independent risk factor for poorer graft and patient outcomes. Patients who have first graft failure should probably receive $\mathrm{ABO}$ incompatible kidney transplantation as a second transplant as soon as possible, if they have potential ABO-incompatible donor candidates.

$\mathrm{ABO}$-incompatible kidney transplantation requires intensive immunosuppressive therapy including antibody removal and $\mathrm{B}$ cell depletion for desensitization. A recent meta-analysis showed that $49 \%$ of reported causes of death in patients who were $\mathrm{ABO}$-incompatible were of infectious origin versus only $13 \%$ in patients who were $\mathrm{ABO}$ compatible [23]. The prevalence of infectious disease in $\mathrm{ABO}$-incompatible kidney transplantation may be higher than that in ABO-compatible kidney transplantation. In our study, all 3 recipients received administration of RIT and splenectomy. Two patients received both splenectomy and administration of RIT at the second transplant due to high anti-A/B antibody titers (Case 1) and preformed DSA (Case 2). One patient (Case 3), who underwent $\mathrm{ABO}$-incompatible kidney transplantation twice, received splenectomy at the initial transplant and RIT administration at the second transplant. The immunosuppressants, which the patients received over 2 kidney 
transplants, may cause over-immunosuppression, inducing malignancy and serious opportunistic infection. Case 3 was affected by intractable colitis by very late-onset $\mathrm{CMV}$ infection before the first graft failure, and it was considered to be over-immunosuppression due splenectomy 10 years before. Therefore, we modified her regimen so that she received EVL with Tac minimization as immunosuppressive therapy at the second transplant. EVL exhibits little nephrotoxicity and pleiotropic effects, such as antiproliferative, antineoplastic, antiviral, and antiatherosclerotic properties [24-27]. Her post second transplant clinical course has been satisfactory without CMV infection. A previous report demonstrated that as with mycophenolate mofetil, EVL was capable of inhibiting human B-lymphocyte function and activation including B-lymphocyte proliferation, apoptosis, and immunoglobulin production [28]. Moreover, our previous report showed that EVL may be a safe and effective alternative for ABOincompatible kidney transplant recipients requiring temporary discontinuation of mycophenolate mofetil [29]. EVL may be a favorable immunosuppressant for second transplantation, possibly preventing antibody-mediated rejection, malignancy, and viral infection.

The present study might have limitations because of the small number of cases and the fact that it is a retrospective study. However, there have been no reports on ABO-incompatible kidney transplantation as a second transplant. Although this is a pilot study, this may be the first demonstration on second $\mathrm{ABO}$-incompatible kidney transplantation. In this study, second $\mathrm{ABO}$-incompatible kidney transplantation could be accomplished without severe adverse events. To confirm these findings, further prospective cohort trials with a larger number of patients are needed in future.

In conclusion, all of our patients underwent successful second $\mathrm{ABO}$-incompatible kidney transplantation without severe complications or rejection, although this procedure can carry a high immunological risk due to $\mathrm{ABO}$ - incompatibility and elevated levels of preformed HLA antibodies. ABO-incompatible kidney transplantation may be acceptable for patients who need a second renal replacement therapy after their initial graft failure.

\section{Acknowledgment}

None.

\section{Statement of Ethics}

This study was approved by the Ethics Committee of Osaka City University Graduate School of Medicine (No.3957). Opt-outconsent was obtained instead of written informed consent. We provided patients with information explaining the proposed research plan (the purpose, required individual data, and duration of research) by means of an information website of our hospital and gave them the opportunity of opt-out. All the procedures were in accordance with the Helsinki Declaration of 2000 and the Declaration of Istanbul 2008.

\section{Disclosure Statement}

The authors declare that they have no conflicts of interest to disclose.

\section{Funding Sources}

There is no funding source applicable to this study.

\section{Authors Contribution}

We would like to note that among the authors, J.U., A.K., and T.N. designed the study, and J.U., A.K., and T.N. wrote the paper. J.U., S.N., K.M., T.I., and K.K. participated in the patients' followup and collected data, while T.N., Y.Y., N.K., H.S., Y.T., and N.K. analyzed the data. All authors have made significant contributions to this paper and confirm the data to be beneficial for physicians involved in kidney transplantation.

\section{References}

1 Yagisawa T, Mieno M, Yoshimura N, Yuzawa $\mathrm{K}$, Takahara S. Current status of kidney transplantation in Japan in 2015: the data of the Kidney Transplant Registry Committee, Japanese Society for Clinical Renal Transplantation and the Japan Society for Transplantation. Renal Replacement Therapy. 2016 Dec; 2(1):68.

2 Nankivell BJ, Borrows RJ, Fung CL, O'Connell PJ, Allen RD, Chapman JR. The natural history of chronic allograft nephropathy. N Engl J Med. 2003 Dec;349(24):232633.

3 Rao PS, Schaubel DE, Wei G, Fenton SS. Evaluating the survival benefit of kidney retransplantation. Transplantation. 2006 Sep;82(5): 669-74.

4 Takahashi K, Saito K, Takahara S, Okuyama A, Tanabe K, Toma H, et al.; Japanese ABOIncompatible Kidney Transplantation Com- mittee. Excellent long-term outcome of ABOincompatible living donor kidney transplantation in Japan. Am J Transplant. 2004 Jul; 4(7):1089-96.

5 Okumi M, Toki D, Nozaki T, Shimizu T, Shirakawa $\mathrm{H}$, Omoto $\mathrm{K}$, et al. ABO-Incompatible Living Kidney Transplants: Evolution of Outcomes and Immunosuppressive Management. Am J Transplant. 2016 Mar;16(3):88696. 
6 Trébern-Launay K, Foucher Y, Giral M, Legendre C, Kreis H, Kessler M, et al. Poor longterm outcome in second kidney transplantation: a delayed event. PLoS One. 2012;7(10): e47915.

7 Kosoku A, Uchida J, Kabei K, Nishide S, Shimada H, Iwai T, et al. Favorable Outcomes of Elderly ABO-Incompatible Kidney Transplantation-Pilot Single Center Experience. Urol Int. 2018;101(4):459-66.

8 Uchida J, Iwai T, Kabei K, Nishide S, Yamasaki T, Kuwabara N, et al. ABO-Incompatible Living Kidney Transplant Recipients from Spousal Donors Receiving Rituximab. Urol Int. 2016;97(4):457-65.

9 Uchida J, Iwai T, Machida Y, Kuwabara N, Kabei K, Murao M, et al. ABO-incompatible kidney transplantation in elderly patients over 60 years of age. Int Urol Nephrol. 2012 Oct;44(5):1563-70.

10 Uchida J, Kuwabara N, Machida Y, Iwai T, Naganuma T, Kumada N, et al. Excellent outcomes of ABO-incompatible kidney transplantation: a single-center experience. Transplant Proc. 2012 Jan;44(1):204-9.

11 Uchida J, Machida Y, Iwai T, Kuwabara N, Iguchi T, Naganuma T, et al. Clinical outcome of $\mathrm{ABO}$-incompatible living unrelated donor kidney transplantation. Urol Int. 2011;86(3): $307-14$.

12 Uchida J, Machida Y, Iwai T, Naganuma T, Kitamoto K, Iguchi T, et al. Desensitization protocol in highly HLA-sensitized and ABOincompatible high titer kidney transplantation. Transplant Proc. 2010 Dec;42(10):3998-4002.

13 Uchida J, Iwai T, Kato M, Machida Y, Naganuma T, Kumada N, et al. A novel approach to successful $\mathrm{ABO}$-incompatible high-titer renal transplantation. Transplant Proc. 2008 Sep;40(7):2285-8.

14 Kosoku A, Uchida J, Nishide S, Kabei K, Shimada $\mathrm{H}$, Iwai $\mathrm{T}$, et al. ABO-incompatible kid- ney transplantation as a renal replacement therapy-A single low-volume center experience in Japan. PLoS One. 2018 Dec; 13(12):e0208638

15 Terasaki PI, Cecka JM, Gjertson DW, Takemoto S. High survival rates of kidney transplants from spousal and living unrelated donors. N Engl J Med. 1995 Aug;333(6):333-6.

16 Rao PS, Schaubel DE, Jia X, Li S, Port FK, Saran R. Survival on dialysis post-kidney transplant failure: results from the Scientific Registry of Transplant Recipients. Am J Kidney Dis. 2007 Feb;49(2):294-300.

17 Gjertson DW. A multi-factor analysis of kidney regraft outcomes.Clin Transpl. 2002: $335-49$.

18 Montgomery RA, Lonze BE, King KE, Kraus ES, Kucirka LM, Locke JE, et al. Desensitization in HLA-incompatible kidney recipients and survival. N Engl J Med. 2011 Jul;365(4): $318-26$.

19 Orandi BJ, Luo X, Massie AB, GaronzikWang JM, Lonze BE, Ahmed R, et al. Survival Benefit with Kidney Transplants from HLAIncompatible Live Donors. N Engl J Med. 2016 Mar;374(10):940-50.

20 Meier-Kriesche HU, Kaplan B. Waiting time on dialysis as the strongest modifiable risk factor for renal transplant outcomes: a paired donor kidney analysis. Transplantation. 2002 Nov;74(10):1377-81.

21 Wong G, Chua S, Chadban SJ, Clayton P, Pilmore $\mathrm{H}$, Hughes PD, et al. Waiting Time Between Failure of First Graft and Second Kidney Transplant and Graft and Patient Survival. Transplantation. 2016 Aug; 100(8): 1767-75.

22 Girerd S, Girerd N, Duarte K, Giral M, Legendre C, Mourad G, et al. Preemptive second kidney transplantation is associated with better graft survival compared with non-preemptive second transplantation: a multi- center French 2000-2014 cohort study. Transpl Int. 2018 Apr;31(4):408-23.

23 de Weerd AE, Betjes MG. ABO-Incompatible Kidney Transplant Outcomes: A Meta-Analysis. Clin J Am Soc Nephrol. 2018 Aug;13(8): 1234-43.

24 Schuler W, Sedrani R, Cottens S, Häberlin B, Schulz M, Schuurman HJ, et al. SDZ RAD, a new rapamycin derivative: pharmacological properties in vitro and in vivo. Transplantation. 1997 Jul;64(1):36-42.

25 Euvrard S, Morelon E, Rostaing L, Goffin E, Brocard A, Tromme I, et al.; TUMORAPA Study Group. Sirolimus and secondary skincancer prevention in kidney transplantation. N Engl J Med. 2012 Jul;367(4):329-39.

26 Brennan DC, Legendre C, Patel D, Mange $\mathrm{K}$, Wiland A, McCague K, et al. Cytomegalovirus incidence between everolimus versus mycophenolate in de novo renal transplants: pooled analysis of three clinical trials. Am J Transplant. 2011 Nov;11(11): 2453-62.

27 Mueller MA, Beutner F, Teupser D, Ceglarek $\mathrm{U}$, Thiery J. Prevention of atherosclerosis by the MTOR inhibitor everolimus in LDLR-/mice despite severe hypercholesterolemia. Atherosclerosis. 2008 May;198(1):39-48.

28 Matz M, Lehnert M, Lorkowski C, Fabritius $\mathrm{K}$, Unterwalder N, Doueiri S, et al. Effects of sotrastaurin, mycophenolic acid and everolimus on human B-lymphocyte function and activation. Transpl Int. 2012 Oct;25(10): 1106-16

29 Uchida J, Machida Y, Iwai T, Kuwabara N, Kabei K, Naganuma T, et al. Conversion of stable ABO-incompatible kidney transplant recipients from mycophenolate mofetil with standard exposure calcineurin inhibitors (CNIs) to everolimus with very low exposure CNIs-a short-term pilot study. Clin Transplant. 2014 Jan;28(1):80-7. 